\title{
Hubungan Keragaman Pangan dengan Kejadian Stunting
}

\author{
Wulan Margiana, Evicenna N Riani, Ima Syamrotul M \\ Email: wulanmargiana@ump.ac.id \\ Kebidanan Sarjana, Universitas Muhammadiyah Purwokerto, Indonesia \\ Jl. Soepardjo Roestam Km 7 Sokaraja
}

\begin{abstract}
Abstrak
Stunting merupakan permasalahan gizi di dunia, terdapat 165 juta balita di dunia dalam kondisi pendek (stunting). Delapan puluh persen balita stunting tersebar pada 14 negara di dunia dan Indonesia menduduki rangking ke lima negara dengan jumah stunting terbesar. Data stunting di Indonesia menunjukkan bahwa prevalensi stunting secara nasional terjadi peningkatan dari 35,6\% (2010) menjadi 37,2 \% (tahun2013). Kondisi tersebut menggambarkan bahwa sekitar 8,9 juta anak Indonesia mengalami pertumbuhan tidak maksimal atau satu dari tiga anak mengalami stunting. Berdasarkan kajian survey stunting yang dilakukan tahun 2018, Kabupaten Banyumas termasuk dalam 100 besar wilayah Kabupaten/Kota dengan angka stunting tertinggi di Indonesia. Banyumas termasuk daerah yang terpilih menjadi prioritas penanganan kasus stunting balita di Jawa Tengah bersama dengan sembilan kabupaten atau kota lainnya. Desa Rempoah Baturaden merupakan salah satu target prioritas sasaran dalam upaya penurunan stunting di kabupaten Banyumas.Tujuan penelitian ini adalahUntuk mengetahui Hubungan keragaman pangan dengan kejadian stunting di desa Rempoah Baturaden Kabupaten Banyumas.Metode penelitain yang digunakan adalah penelitian observasi analitik, dengan desain Cross Sectional. Berdasarkan hasil menunjukan bahwa terdapat hubungan antara keragaman pangan dengan kejadian stunting di Desa Rempoah Baturaden Kabupaten Banyumas.
\end{abstract}

Kata Kunci: stunting; keragaman pangan.

\begin{abstract}
Stunting is a nutritional problem in the world, there are 165 million children under five in the world who are stunted. Eighty percent of children under five with stunting are spread across 14 countries in the world and Indonesia is in the fifth rank of the countries with the largest number of stunting. Stunting data in Indonesia shows that the national prevalence of stunting has increased from $35.6 \%(2010)$ to $37.2 \%$ (2013). This condition illustrates that around 8.9 million Indonesian children experience slow growth or one in three children is stunted. Based on a stunting survey study conducted in 2018, Banyumas Regency is included in the top 100 districts / cities with the highest stunting rate in Indonesia. Banyumas is one of the areas selected to be the priority in handling children under five stunting cases in Central Java along with nine other districts or cities. Rempoah Baturaden Village is one of the priority targets in an effort to reduce stunting in Banyumas district. The purpose of this study was to determine the relationship between food diversity and the incidence of stunting in the village of Rempoah Baturaden, Banyumas Regency. The research method used was analytic observational research, with a cross sectional design. The results show that there is a relationship between food diversity and the incidence of stunting in Rempoah Baturaden Village, Banyumas Regency.
\end{abstract}

Keywords: stunting; food diversity. 
Jurnal Kebidanan Harapan Ibu Pekalongan

\section{Pendahuluan}

Stunting permasalahan gizi di dunia, terdapat 165 juta balita di dunia dalam kondisi pendek (stunting). Delapan puluh persen balita stunting tersebar pada 14 negara di dunia dan Indonesia menduduki rangking ke lima negara dengan jumah stunting terbesar. Data stunting di Indonesia menunjukkan bahwa prevalensi stunting secara nasional terjadi peningkatan dari $35,6 \%$ (2010) menjadi 37,2 \% (tahun2013). Kondisi tersebut menggambarkan bahwa sekitar 8,9 juta anak Indonesia mengalami pertumbumbuhan tidak maksimal atau satu dari tiga anak mengalami stunting. Hasil Pemantauan Status Gizi (PSG) tahun 2017 menunjukkan bahwa persentase balita stunting pada kelompok balita $(29,6 \%)$ lebih besar jika dibandingkan dengan usia baduta $(20,1 \%)$.

Berdasarkan kajian survey stunting yang dilakukan tahun 2018, Kabupaten Banyumas termasuk dalam 100 besar wilayah Kabupaten/Kota dengan angka stunting tertinggi di Indonesia. Banyumas termasuk daerah yang terpilih menjadi prioritas penanganan kasus stunting balita di Jawa Tengah bersama dengan sembilan kabupaten atau kota lainnya. Desa Kalibagor merupakan salah satu target prioritas sasaran dalam upaya penurunan stunting di kabupaten Banyumas.

Stunting pada anak dapat mengakibatkan penurunan sistem imunitas tubuh dan meningkatkan risiko terkena penyakit infeksi. Kecenderungan untuk menderita penyakit tekanan darah tinggi, diabetes, jantung dan obesitas akan lebih tinggi ketika anak stunting menjadi dewasa. Anak stunting mempunyai rata-rata IQ 11 point lebih rendah dibandingkan rata-rata anak yang tidak stunting.
Berdasarkan latarbelakang tersebut penelitiingin hubungan keberagaman pangan dan pola asuh makan dengan kejadian stunting pada balita di Desa Kalibagor Kabubaten Banyumas. Peneliti melakukan penelitian inisebagaisalah satu upaya mengurangi angka kejadian stunting.

\section{Metode Penelitian}

Jenis penelitian ini adalah penelitian observasi analitik, dengan desain Cross Sectional. Cross Sectional yaitu jenis penelitian yang menekankan pada waktu pengukuran atau observasi data dalam satu kali pada satu waktu yang dilakukan pada variabel terikat dan variabel bebas. Pendekatan ini digunakan untuk menlihat hubungan antara variabel satu dengan variabel lainnya.

\section{Hasil dan Pembahasan}

\section{Karakteristik Subjek}

Jumlah subjek pada penelitian ini berjumlah 30 balita dan didominasi oleh balita laki-laki. Umur balita terbanyak adalah balita yang berumur 13-24 bulan. Subjek disajikan pada table 1 .

Tabel 1. Distribusi frekuensi responden berdasarkan umur dan jenis kelamin

\begin{tabular}{clllll}
\hline No & Variabel & Kejadian & $\%$ & Total & $\%$ \\
\hline 1. & Umur & & & & \\
& $0-12$ & 3 & 10 & 3 & 10 \\
& $13-24$ & 10 & 33,3 & 10 & 33,3 \\
& $25-36$ & 7 & 23,3 & 7 & 23,3 \\
& $37-48$ & 6 & 20 & 6 & 20 \\
& $49-60$ & 4 & 13,3 & 4 & 13,3 \\
\hline 2 & Jenis & & & & \\
& Kelamin & & & & \\
& Laki-laki & 17 & 56,7 & 17 & 56,7 \\
& Perempuan & 13 & 43,3 & 13 & 43,3 \\
\hline
\end{tabular}

Sumber: Data Primer

Pada karakteristik keragaman pangan terdapat 14 balita $(46,7 \%)$ yang makan makanan beragam dan terdapat 16 balita $(53,3 \%)$ yang 
Jurnal Kebidanan Harapan Ibu Pekalongan

makan makanan tidak beragam. Subjek disajikan pada tabel 2.

Tabel 2. Distribusi frekuensi keragaman pangan

\begin{tabular}{llll}
\hline No & Keragaman Pangan & f & $\%$ \\
\hline 1. & Beragam & 14 & 46,7 \\
2. & Tidak beragam & 16 & 53,3 \\
\hline & Jumlah & 30 & 100 \\
\hline
\end{tabular}

Sumber :Data Primer

Pada kejadian stunting terdapat 7 $(23,33 \%)$ balita yang normal dan terdapat $23(76,67 \%)$ balita yang mengalami stunting. Subjek disajikan pada tabel 3 .

Tabel 3. Distribusi Frekuensi kejadian Stunting

\begin{tabular}{llll}
\hline No & Stunting & f & $\%$ \\
\hline 1. & Stunting & 23 & 76,67 \\
2. & Normal & 7 & 23,33 \\
\hline & Jumlah & 30 & 100 \\
\hline
\end{tabular}

Sumber: Data Primer

Dari hasil analisis Chi-square menunjukan bahwa $(p=0,001)$ yang artinya bahwa adanya hubungan keragaman pangan dengan kejadian stunting. Subjek disajikan pada tabel 4

Tabel 4. Hubungan Keragaman Pangan dengan Kejadian Stunting

\begin{tabular}{lllll}
\hline No & Variabel & Stunting & $\begin{array}{l}\text { Tidak } \\
\text { Stunting }\end{array}$ & Total \\
\hline 1 & Beragam & 7 & 7 & 14 \\
\hline 2 & $\begin{array}{l}\text { Tidak } \\
\text { Beragam }\end{array}$ & 16 & 0 & 16 \\
\hline & Total & 23 & 7 & 30 \\
\hline
\end{tabular}

Sumber: Data Primer

Hasil penelitian menunjukan ada hubungan antara keragaman pangan dengan kejadian stunting di desa Rempoah Baturaden. Temuan penelitian ini menunjukan hasil yang relevan dengan penelitian Prastia, Listyandini (2020) yang berjudul Keragaman Pangan Berhubungan dengan Stunting pada Anak 6-24 Bulan. Hasil penelitian ini menunjukan keragaman pangan memiliki hubungan dengan stunting anak usia 6-24 bulan berdasarkan uji statistic bivariat. Anak dengan konsumsi pangan tidak beragam beresiko 3 kali lebih besar mengalami stunting dibandingkan dengan anak yang mengkonsumsi makanan yang beragam. Penelitian relevan lainnya oleh Wantina, Mira dkk berjudul Keragaman Konsumsi Pangan sebagai Faktor Risiko Stunting pada Balita Usia 6-24 Bulan dengan hasil penelitian berhubungan antara kergaman konsumsi pangan dengan stunting pada balita 6-24 bulan.

\section{Kesimpulan}

Terdapat Hubungan antara keragaman pangan dengan kejadian stunting di desa Rempoah Baturaden

\section{Daftar Pustaka}

[1] Widyaningsih, Novita Nining. Keragaman Pangan, Pola Asuh makandan Kejadian Stunting pada Balita usia 24-59 bulan. Jurnal Gizi Indonesia, 2018.

[2] Dinkes Banyumas. Profil Kesehatan Kabupaten Banyumas Tahun 2015. 2016.

[3] Departemen Kesehatan RI. Kecenderungan masalah gizi dan tantangan di masa datang. Jakarta, 2004.

[4] Puspitasari FD dkk. Hubungan antara status gizi dan faktor sosio demografi dengan kemampuan kognitif anak sekolah dasar di daerah endemis GAKI.Gizi Indon. 34(1), pp. 52-60, 2011. 
Jurnal Kebidanan Harapan Ibu Pekalongan

[5] Hartati S. Hubungan Prestasi Belajar dengan Anak Stunted di Kecamatan Pajangan Kabupaten Bantul Daerah Istimewa Yogyakarta. [Tesis]. Yogyakarta: Universitas Gadjah Mada, 2011.

[6] Pristia, Tika Noor dan Rahma Listyadini. Keragaman Pangan Berhubungan dengan Stunting pada Anak Usia 6-24 Bulan. Hearty Jurnal Kesehatan Masyarakat vol. 8 no. 1, 2020.

[7] Wantina, Mira dkk. Keragaman Konsumsi Pangan Sebagai Faktor Risiko Stunting pada Balita Usia 6-24 Bulan. Argipa vol. 2, no. 2, 2017. 